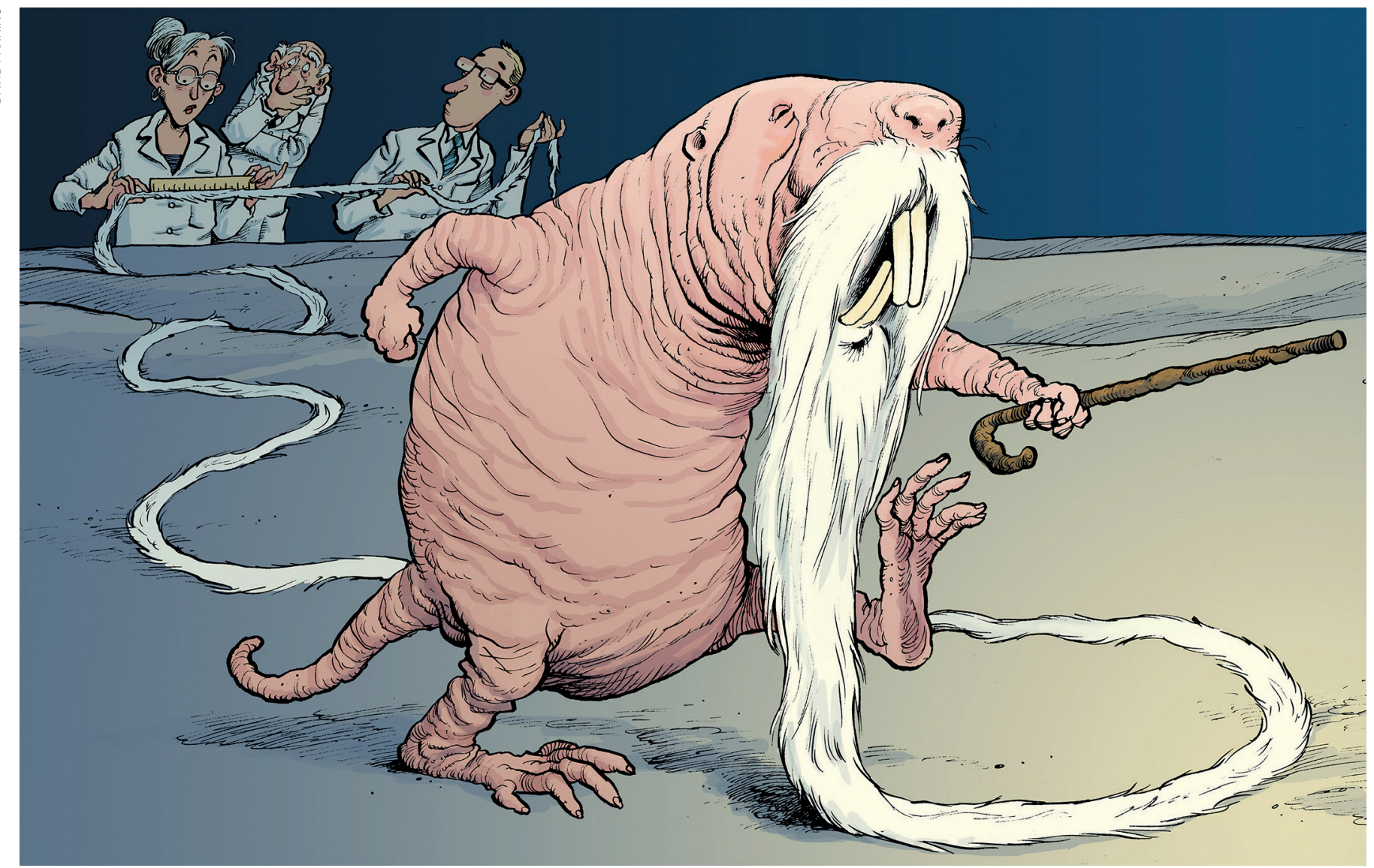

\title{
Offbeat approaches to cancer research
}

\author{
Creative thinking can pay dividends for researchers taking on cancer.
}

\author{
BY NIC FLEMING
}

ancer was responsible for an estimated 9.6 million deaths in 2018. Finding new ways to combat it is an important endeavour. Scientists are making advances through a variety of research methods; here, five individuals share how they've built careers in cancer research while taking innovative approaches to this problem.

\section{VERA GORBUNOVA}

\section{Stay open-minded}

\section{Comparative biologist at the University} of Rochester in New York.

The naked mole rat (Heterocephalus glaber) is a remarkable creature in more ways than one. With its large, goofy incisors and waves of pale pink wrinkles, it is unlikely to win any beauty pageants. But the naked mole rat does have some things going for it. It can live for more than 30 years. And it almost never gets cancer.

When Vera Gorbunova set up her laboratory to investigate ageing, she looked beyond the mouse and rat models usually deployed in the field. "Try to disassociate yourself from existing approaches and think about the shortest path to the answer," says Gorbunova. "If you want to understand how to avoid cancer, study animals that don't get cancer. If you want to study ageing, study animals that live a long time."

Gorbunova and her colleagues cultured connective tissue cells from long-lived animal species. In a 2009 study $^{1}$, they noted that a process in natural anticancer defences called contact inhibition, which prevents cells from dividing when they reach a certain density, occurs at a much lower cell density in naked mole rats.

The researchers found that a thick fluid seen in mole-rat cell cultures was hyaluronan - a substance with a wide range of functions in mammals, including in tissue formation, wound repair and joint lubrication - and that the mole rat's hyaluronan molecules weigh five times more than those of human and mouse, and degrade more slowly ${ }^{2}$. Both these differences slow the growth of precancerous cells and protect naked mole rats from cancer.

Gorbunova's group is now trying to mimic the mole rat's cancer resistance and reproduce it in humans by identifying small molecules that inhibit hyaluronan-degrading enzymes.

Gorbunova acknowledges that it can be hard for researchers to head into uncharted territory when they are starting their careers. She suggests early-career scientists pursue a main project that is likely to produce publishable results, and another that is more outside the box. She stresses the need to stay open-minded. "When we began looking 
- at naked mole rats, we didn't really know what we were looking for. It's important not to ignore unexpected results that don't fit your hypothesis, because most of the time nature is smarter than us."

\section{BERT VAN DER HORST}

\section{Choose posts carefully} Chronobiologist at the Erasmus Medical
Centre in Rotterdam, the Netherlands.

During his postdoc at the Erasmus Medical Centre in Rotterdam, the Netherlands, in the 1990s, Bert van der Horst studied Cockayne syndrome, a rare condition in which skin is highly sensitive to the DNA damage caused by ultraviolet light.

He went on to investigate the subject more broadly. When he generated mice without two genes that were thought to be important for the repair of direct DNA damage caused by UV light, the genes did not have the DNA-repair function he had expected. Van der Horst later discovered that the genes - CRY1 and CRY2 - instead have essential roles in maintaining mammalian circadian rhythms ${ }^{3}$.

"I was lucky to have a supervisor who, even though he was sceptical, allowed me to explore my ideas," says van der Horst. "I say to my students, 'Keep your eyes open for the unexpected, and even if others think your idea is ridiculous, don't give up."

The publication of the gene discovery in 1999 was a turning point in Van der Horst's career, and he has worked on chronobiology, and its relationship with disease, ever since.

People whose circadian rhythms are interrupted, such as those who work night shifts, are thought to be at elevated risk of cancer, but longterm human-intervention studies are difficult for ethical reasons.

Animal models are the next best thing. In 2015, van der Horst showed that female mice that were genetically disposed to grow tumours and that were exposed to light-dark cycles that switched weekly developed the tumours sooner and gained $17 \%$ more weight than those kept in normal light conditions ${ }^{4}$.

His group has also genetically altered mice to be either early or late risers, and it is investigating whether making the mice live contrary to their natural rhythms is carcinogenic. In collaboration with others, van der Horst is also studying the idea that chemotherapy can be more effective and have fewer side effects at certain times of the day.

Van der Horst says early-career scientists should be careful when selecting the posts they apply for. "Once you are a postdoc, you need a certain level of freedom. Early-career scientists might be better with a supervisor who allows them time and space to explore their own thoughts and ideas alongside their main projects."

\section{ANANT MADABHUSHI Take a risk}

\section{Biomedical engineer at Case Western Reserve University in Cleveland, Ohio.}

Regular screening of people at high risk of certain cancers saves lives. But computer tomography (CT) scans and X-rays often flag up benign lumps and nodules, and physicians can find it hard to visually distinguish these from malignant growths. For many people, this means unnecessary anxiety, more tests and surgical interventions. And for health-care systems, it means wasted money and staff time.

Anant Madabhushi says computer algorithms that can analyse key data from medical images could greatly improve the accuracy of cancer diagnosis.

Non-small-cell lung cancer adenocarcinomas, which develop in glandular cells, and benign concentrations of immune cells that form during inflammation, called granulomas, can be hard to tell apart. Two algorithms developed by Madabhushi's group analysed data from the CT scans of 290 people with one condition or the other. The first algorithm, which assessed the shape, texture and density of nodules and features around them, got it right $80 \%$ of the time $^{5}$. The second, which analysed how twisted nearby blood vessels were (a marker of malignancy), scored $85 \%{ }^{6}$. This compared with $60 \%$ and $61 \%$ for a pulmonologist and a radiologist.

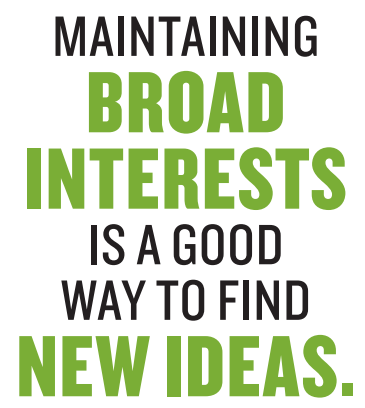

Madabhushi is using his approach to determine prognosis and optimum treatments for people with lung, head and neck, prostate or breast cancers. He says the multidisciplinary nature of his field helped him gain an early understanding of the importance of the environment around tumours, including blood vessels and immune cells. During his PhD at the University of Pennsylvania in Philadelphia he worked alongside pathologists and radiologists deploying artificial intelligence (AI) to identify prostate cancer in magnetic resonance imaging (MRI) scans.

"Working closely with experts in other fields gave me an appreciation of the multiscale nature of disease," he says. "Any time I look at a scan, I'm also trying to visualize what it is going on microscopically and histologically."

Madabhushi, who has since started a company to move his work forwards, says that those who want to break new ground need to have the courage of their convictions. "At the end of the day, if you've thought things through carefully and your instinct goes against the advice you're getting, you have to be willing to back yourself and take a risk."

\section{ELEANOR STRIDE Don't be a clone}

\section{Mechanical engineer at the Institute of Biomedical Engineering, University of Oxford, UK.}

Chemotherapy treatments often cause painful and unpleasant side effects, such as nausea and hair loss. Improved, targeted therapies that unleash their payloads only once they reach tumour sites are seen by many researchers as the route to better efficacy and reduced side effects.

Among these researchers is Eleanor Stride, a mechanical engineer who has found that going against the grain can be rewarding. Stride became interested in the therapeutic potential of tiny bubbles of gas during her $\mathrm{PhD}$ at University College London. The 'microbubbles' she studies are 1-2 micrometres in diameter and are coated with a lipid to prevent the contents escaping.

Stride learnt early on that crossing conventional discipline boundaries can be challenging. "Going to [cancer] conferences was harder because no one knew me or my supervisor," she says, "as was getting published in high-impact journals, because I didn't have the track record and network of people to rely on."

Since then, Stride, who joined the University of Oxford's Institute of Biomedical Engineering in 2011, has made a series of advances. Solid tumours trigger the growth of abnormal blood vessels and reduce oxygen supplies in affected tissue, which can prevent drugs reaching those areas. In 2015, Stride and her collaborators showed that rose bengal, a dye going through clinical trials as a cancer drug, is more effective at shrinking pancreatic tumours in mice when it is attached to microbubbles of oxygen that are burst at the tumour site using ultrasound ${ }^{7}$.

The team went on to show that this effect could be enhanced by attaching the existing pancreatic-cancer therapies fluorouracil and gemcitabine to the microbubbles ${ }^{8,9}$. The group shrank tumours further by adding magnetic nanoparticles to the bubbles to push them closer to their targets using magnets outside the body ${ }^{10}$. Stride and her colleagues are seeking funding to start human trials. 


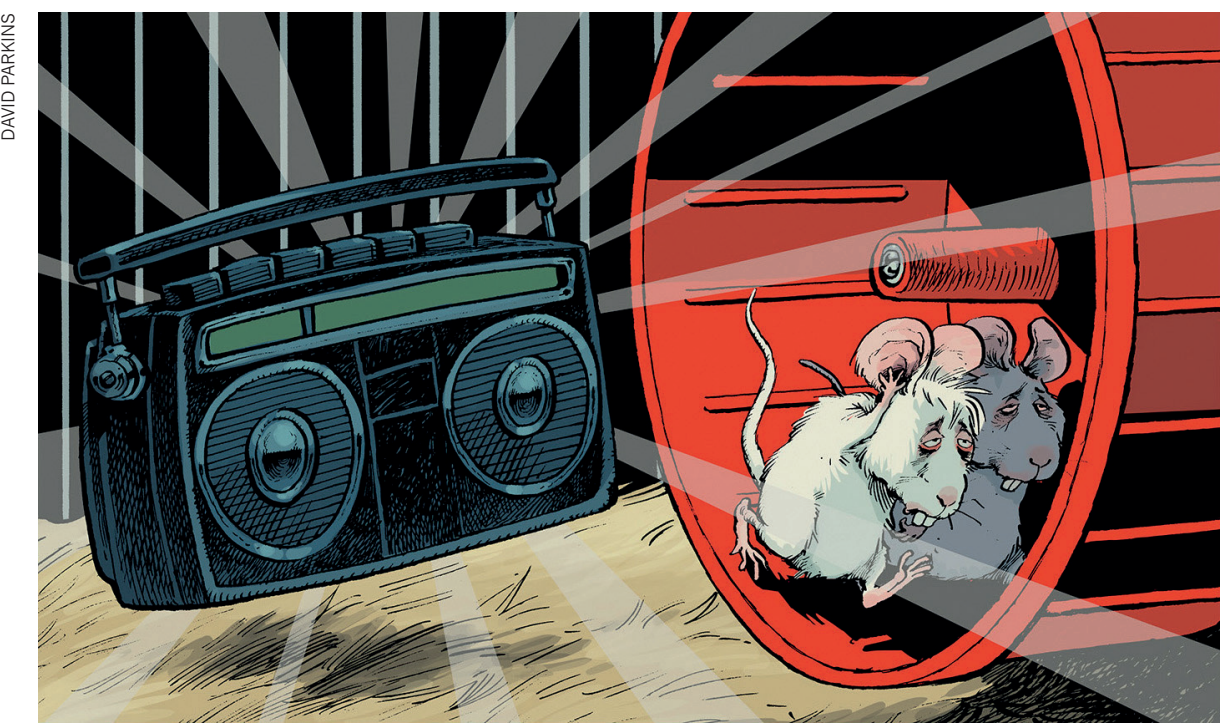

Although early-career scientists might be able to speed their progress by following closely in the footsteps of their supervisor, there are also potential downsides, says Stride. "There's a danger that you become a bit of clone, and you don't necessarily get the recognition for what you've done." She advises those who want to be creative to "keep an open mind, talk to colleagues, be sociable around university and go to seminars in subjects you know little about. It's easier said than done, given how pressed for time we all are, but maintaining broad interests is a good way to find new ideas."

HARRYBULSTRODE

\section{Don't specialize too soon}

\section{Neurosurgeon and researcher at the University of Cambridge, UK.}

The 2015-16 Zika epidemic resulted in more than 500,000 suspected cases across the Americas. Symptoms in adults were mostly mild or absent, whereas thousands of babies whose mothers caught the virus during pregnancy had serious neurological damage; the virus blocks cellular processes that are key to healthy brain development in the womb.

This finding was intriguing to scientists working on ways to treat brain tumours called glioblastomas. These tumours hijack the same molecular mechanisms involved in fetal brain development to drive their rapid growth and spread. As the Zika epidemic hit the headlines, Harry Bulstrode was finalizing his $\mathrm{PhD}$, studying the proteins that control the genes involved in driving the growth of glioblastomas.

"If Zika can switch off the specific rapid cell division and migration we see in glioblastomas, it represents precisely the targeted therapy we have been looking for," says Bulstrode.
Using a dangerous virus to fight cancer was always likely to encounter safety concerns. But, after his $\mathrm{PhD}$, Bulstrode wanted to complete his clinical training as a neurosurgeon and continue doing research, so an unconventional project suited him. "With my clinical commitments, I knew I couldn't compete in already mature fields, so I had to go a little left field."

His gamble paid off. In 2017, he was awarded a $£ 200,000$ (US\$264,000) Cancer Research UK Pioneer Award to study whether the molecular arsenal that Zika uses against developing brains can be used to combat glioblastomas. Later that year, however, a US group published a study ${ }^{11}$ showing how Zika killed off glioblastoma stem cells, but left other cells unscathed in cell cultures, and that mice with glioblastomas survived for longer when infected with a form of the virus.

Bulstrode has changed tack. His small group at the Wellcome-Medical Research Council Cambridge Stem Cell Institute is now finding out which types of neural stem cell are susceptible to Zika to find potential drug targets.

$\mathrm{He}$ advises those who want to innovate in research to avoid specializing too soon. "In some big labs now, you have $\mathrm{PhD}$ students coming through who specialize in highly specific techniques," he says. "That's going to make it difficult for them to exploit new ideas."

Nic Fleming is a freelance science writer based in Bristol, UK.

1. Seluanov, A. et al. Proc. Natl Acad. Sci. USA 106, 19352-19357 (2009)

2. Tiann, X. et al. Nature 499 , 346-349 (2013)

3. van der Horst, G. T. J. et al. Nature 398, 627-630 (1999).

4. Van Dycke, K. C. G. et al. Curr. Biol. 25, 1932-1937 (2015).

5. Beig, N. et al. Radiology 290, 783-792 (2019).

6. Alilou, M. et al. Sci. Rep. 8, 15290 (2018).

7. McEwan, C. et al. J. Control. Release 10, 51-56 (2015).

8. McEwan, C. et al. Biomaterials 80, 20-32 (2016).

9. Nesbitt, H. et al. J. Control. Release 279, 8-16 (2018).

10.Sheng, Y. et al. J. Control. Release 262, 192-200 (2017).

11.Zhu, Z. et al. J. Exp. Med. 214, 2843-2857 (2017).

\section{Be in charge of your next career move}

\section{Search for your new role quickly by discipline, country, salary and more on}

naturecareers.com 